\title{
China e Japão em disputas pelas ilhas Senkaku/Diaoyu, conflito inerente ou solução diplomática negociada?
}

China and Japan in disputes over Seneku/Diaoyu islands, inherent conflict or negotiated diplomatic solution?

\section{Jorge Henrique Araujo Medeiros ${ }^{1}$}

\begin{abstract}
RESUMO
o presente artigo tem como objetivo, abordar as disputas territoriais marítimas envolvendo a China e o Japão pelas ilhas Senkaku/Diaoyu, abordando os conceitos teóricos das Fimbrias de Spykman (1942), pretende-se verificar seus desdobramentos, buscando fazer uma análise geopolítica sobre a região.
\end{abstract}

Palavras-chaves: Territórios; poder e segurança.

\section{ABSTRACT}

This article aims to address the maritime territorial disputes involving China and Japan the Senkaku / Diaoyu islands, approaching the theoretical concepts of fimbriae Spykman (1942), intended to verify its consequences, seeking to make a geopolitical analysis of the region.

Keywords: Territories; power and security.

\section{CONSIDERAÇÕES INICIAIS}

As disputas por territórios marítimos analisadas neste artigo, não tem como destaque a extensão dos territórios disputados ou mesmo no seu valor histórico geoestratégico, mas sim na capacidade bélica disponível entre os envolvidos, China, Japão e EUA. A China, segundo a Global Firepower Index (GFP, 2015), possui a terceira maior foça armada do mundo, ficando atrás apenas dos EUA e da Rússia. O Japão situa-se como a nona maior foça armada do mundo (GFP, 2015). Mas, através do Tratado de Mutua Cooperação e Segurança firmado entre os Estados Unidos e Japão (1952), coloca incondicionalmente os EUA como aliado e defensor do Japão no caso de ataque. Logo nos deparamos neste teatro de ações,

\footnotetext{
${ }^{1}$ Bacharel em Relações Internacionais, UNINTER, Curitiba, Brasil e membro do grupo de pesquisa em defesa e segurança.
} 
com três das maiores forças armadas do mundo, sendo que duas delas detém poder de dissuasão nuclear.

\section{O Conceito das teorias das Fimbrias de Spykman e o valor da contenção}

A teoria das fimbrias, idealizada pelo professor Nicholas John Spykman (1942), Doutor em filosofia e diretor do "Instituto de Relações Internacionais" de Yale, nos EUA, foi fundamentada a partir de seus estudos sobre a teoria do poder terrestre de Mackinder, apresentada no seu artigo The Geographical Pivot of History (1904), preconizava a ideia de que quem dominasse o "Coração da Terra" 2 dominaria o mundo, define que apenas o poder marítimo desenvolvido por Mahan em (1890) não seria mais capaz de garantir a supremacia mundial de uma nação.

Mackinder afirma que devido a evolução tecnológica nos meios de "fazer a guerra" e de deslocamento, o poder terrestre passa a ser evidenciado sobre o marítimo, visualiza o domínio da Europa e da Ásia, por alianças estratégicas determinadas pela necessidade de garantir recursos naturais, demográficos e garantidoras dos níveis de industrialização necessário para o intento de expansão. Mackinder visualizava o crescimento militar da Alemanha e da Rússia como uma projeção factual deste novo poder terrestre, podendo este poder avançar para o exterior do Hertland. Sendo assim quem dominar o Hertland, controlaria a ilha mundo e quem controlasse a ilha mundo controlaria o resto do mundo.

Spykman com seu trabalho, America's Strategy in World Politics: The United States and the Balance of Power, New York, Harcourt, Brace and Company (1942), imaginou que a única defesa possível para essa possibilidade não ocorresse, seria ocupando as bordas da "Ilha do Mundo", ou seja, as "fímbrias", que ele denomina na sua teoria como "Rimland". Uma vez ocupado o "Rimland" (fímbrias), não seria possível a expansão para além da "Ilha do Mundo" por parte de quem dominasse o "Coração da Terra" (Heartland), consequentemente, estas forças não teriam acesso ao resto do mundo.

\footnotetext{
2 Coração da Terra ou o Heartland está situado na zona territorial que abrange os continentes europeu e asiático, e que recebe a denominação de Eurásia ou Ilha Mundial. Os nazistas durante a segunda guerra consideravam a expansão e domínio da Europa e da Eurásia como vitais para uma projeção mundial, o bloco Soviético também propagou este conceito de territoriedade.
} 
Spykeman (1942) contextualiza em sua teoria das Fimbrias, que alianças estratégicas militares (poderes navais, terrestres e aéreos) seriam necessários nesta nova realidade geopolítica da guerra fria, defende assim que a projeção militar deveria extrapolar as fronteiras dos EUA e de seus aliados (foco no intervencionismo), buscando um isolamento da "ilha mundo" por ações dispersas mundialmente, contento uma possível expansão comunista para territórios considerados como chaves. A teoria das Fimbrias (contenção), foi amplamente utilizada durante grande parte da guerra fria, visava conter a expansão comunista, criando-se assim organizações internacionais voltadas a este fim específico: a OTAN, localizada no oeste europeu; a OTACEN no centro sul da eurásia e a OTASE, ocupando o oeste asiático (Bonfim, 2005, p.72).

A OTACEN desmorona com a revolução Iraniana e a chegada ao poder dos aiatolás, as guerras da Coreia, do Vietnam e a aproximação dos EUA com a China, inviabilizam a continuidade da OTASE, logo pela lógica, o esfacelamento do bloco soviético indicaria a inclusão da OTAN no rol das organizações de contenção dissolvidas, o que não ocorre de fato, pois a OTAN passa por mudanças conceituais na sua formulação, defendidas primeiro ministro Inglês Tony Blair, no dia 24 de abril de 1999 no Economic Club de Chicago, Estados Unidos (TOLOSSA, 2004). Altera-se o conceito de segurança coletiva e contenção por parte dos membros da União Europeia e passa-se a adotar o uso da OTAN em qualquer parte do mundo, desde que se configurasse como uma resposta a atos de genocídios e/ou garantias aos direitos humanos (TOLOSSA, 2004).

\section{Conceitos sobre a "projeção pacifica" da China, como saída da contenção}

A China demonstra através de sua "projeção pacifica", um grande interesse em garantir um aumento de poder territorial e marítimo, sendo este fortemente lastreado pelo seu atual peso econômico, busca a sua projeção militar sobre regiões contestadas junto a Convenção das Nações Unidas sobre o Direito do Mar (CNUDM). Cheng e Zhang (2002 citados por NOGUEIRA, 2012, p. 10) afirmam que durante a Guerra Fria, verificamos na literatura sobre relações internacionais uma evolução na política externa chinesa definidos em ciclos de aproximadamente 10 anos, períodos relevantes e distintos como: aliança sino-soviética, de 1949 a 1957; frente unida contra o "imperialismo norte americano e o revisionismo soviético" 
de 1958 a 1970; cooperação com os Estados Unidos contra a União soviética de 1970 a 1981; e a adoção de uma política externa independente a partir de 1982.

Segundo Nogueira (2012) no final de 1980 a China se deparou com inúmeros conflitos e turbulências internacionais e domésticas, forçando-a a uma readequação de sua política externa, o colapso dos regimes comunistas e o esfacelamento do bloco soviético (que sofriam a contenção por parte da OTAN) a colocaram como uma isolada ideológica neste período. Cheng e Zhang (2002; citados por NOGUEIRA, 2012, p. 13) afirmam que a partir da década de 1990, surge na China uma estrutura coerente com a intenção Chinesa de busca por uma elevação do seu Status para o de uma superpotência, demonstrando não mais se conformar com a lógica de apenas se moldar e de seguir aos interesses do sistema internacional.

A China passa a atuar a partir da metade década de 1990 reajustando sua política externa em uma clara redefinição do seu papel internacional, tendo uma real percepção na mudança de equilíbrio no poder global, passa a utilizar a partir de então o Comprehensive National Power ${ }^{3}$ como base de projeção (NOGUEIRA, 2012, p. 13). Surgindo segundo Gill (2005 apud NOGUEIRA, 2012, p. 13) em 2003 um novo conceito na política externa chinesa, a chamada "estratégia da ascensão pacífica", o que propicia um ambiente externo favorável ao desenvolvimento e a sua modernização, administrando de forma cuidadosa o crescimento de sua riqueza e o aumento de seu poder, evitando reações negativas de seus vizinhos.

Noqueira (2012) afirma que, ao lidar ainda com a questão do então sistema unipolar do período, a China busca de forma pragmática, conter; cooptar ou amenizar o que os líderes chineses observavam como uma excessiva hegemonia e influência dos Estados Unidos sobre a periferia chinesa, ao mesmo tempo em que evitavam entrar em uma confrontação direta com tais interesses Norte Americanos. A relação Chinesa com Taiwan, demonstra bem está relação pragmática, fundamenta-se na paciência secular chinesa de deixar fluir sem perder o controle (conceito do uso do Wu Wei) ${ }^{4}$, A China ao determina apenas o uso de

\footnotetext{
${ }^{3}$ Comprehensive National Power ou zonghe guoli (em chinês) é um índice que busca medir as capacidades de poder dos países desenvolvidos pela China na Academy of Military Science of the People's Liberation Army (PLA AMS) e a Chinese Academy of Social Sciences (CASS).

${ }^{4}$ Lao-Tsé é tradicionalmente considerado o fundador do taoísmo, movimento com vertentes filosóficas e religiosas distintas designadas por nomes diferentes em chinês: Tao Chia é o termo que se refere ao taoísmo filosófico; Tao Chiao é o termo que se refere ao taoísmo religioso, destaca-se na 
identidade para a transposição entre suas fronteiras e fomentar um constante aumento de suas relações econômicas, busca uma unificação por meios pacíficos e políticos, evitando o discurso internacional da força, mas não a descartando neste caso especifico (PROCÓPIO, 2012, p.71).

China assinou e ratificou os protocolos 2 e 3 do Tratado Rarotonga de 1985 em 1987, demonstrando interesse de manter uma zona livre de armas nucleares no Pacifico Sul e comprovando a Asean +3 , seu comprometimento em estreitar laços econômicos e de segurança, os Estados Unidos assinam o tratado, mas não ratificaram. Desta forma a China se projeta em um aumento escalar de poder sobre a região asiática, projetando seus interesses sobre territórios historicamente contestados por outras nações, ocasionando alterações geopolíticas significativas. A figura 1 abaixo demonstra a área contestada pela China e Japão no mar ao Leste da China e foco de analise deste artigo:

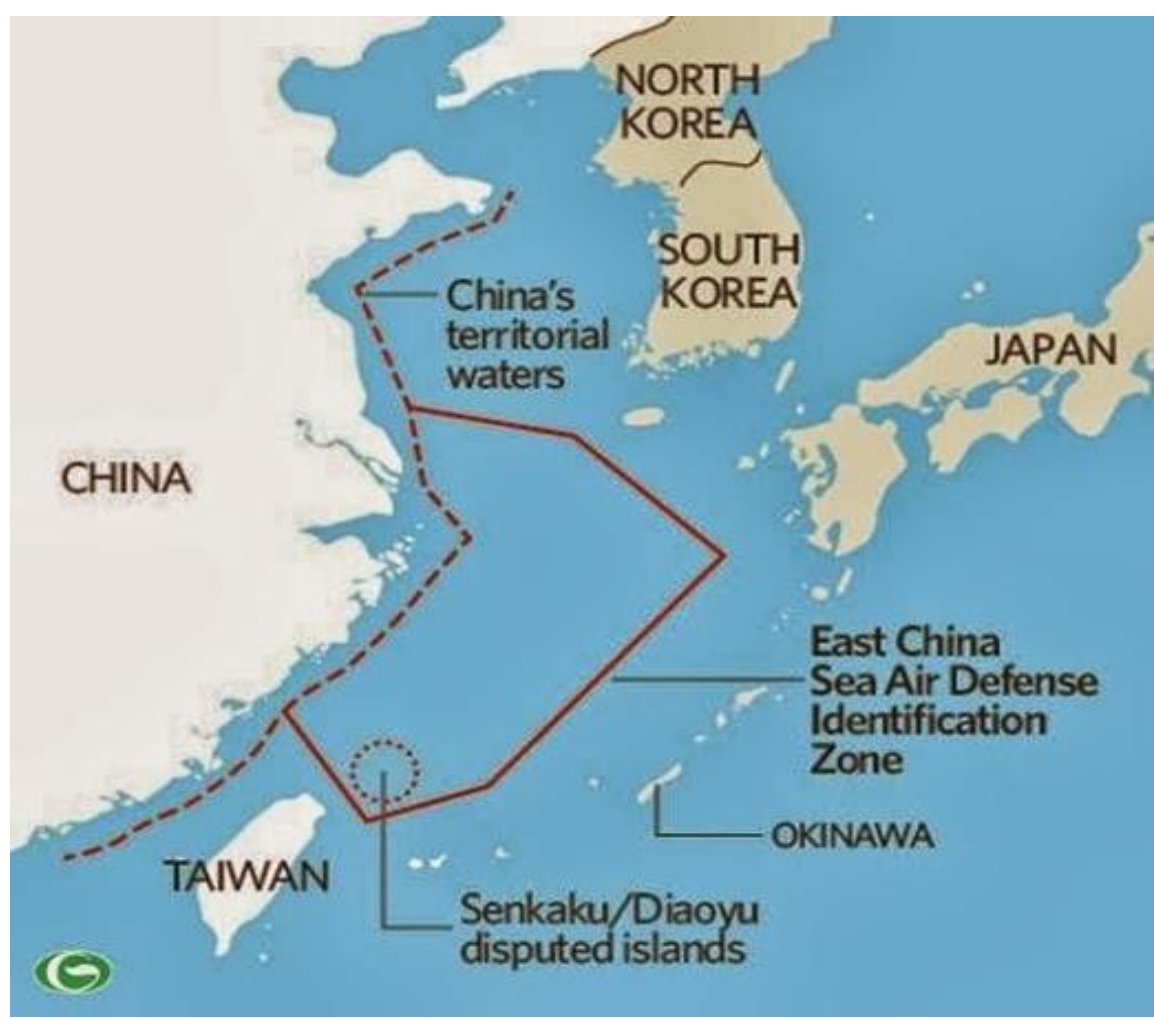

Figura 1. Fonte: Disponível em < http://veja.abril.com.br/noticia/mundo/por-que-oito-ilhotasopoem-china-e-japao >, acesso em 22 de abr. de 2015.

sua filosofia o uso do "não fazer/não atuar" (Wu Wei). É um conceito difícil de entender para os Ocidentais. $\mathrm{O} \mathrm{Wu}$ Wei diz-nos que a forma mais correta de atuar é precisamente não atuar, não forçar a situação; os ocidentais absorvem poucos conceitos do Taoísmo chinês, o mais difundido na cultura ocidental é o do uso do "Yin e o Yang" e sua correlação visual com o "Feng shui". 


\section{Contexto histórico e geopolítico sobre a região.}

Segundo Moisés Lopes de Souza (2014), cinco fatores podem definir o atual contesto geopolítico nos mares da China, todos consolidados no pós-segunda guerra mundial: i) A retirada das tropas Japonesas de todas as suas possessões, com o respectivo aumento da influência Norte Americano, ii) 0 conflito da guerra civil chinesa e seus desdobramentos, iii) 0 processo de descolonização da região, IV) As descobertas de óleo e gás natural nas regiões em litigio e V) o estabelecimento da Convenção das Nações Unidas para o Direito dos Mares (CNUDM), em 1973.

A disputa pelas ilhas data desde 1895, durante a guerra sino-japonesa, com vitória do Japão e assinatura do tratado de Shimonoseki pela então dinastia imperial Qing, sendo este tratado não reconhecido posteriormente com a chegada ao poder do governo do Partido Comunista Chinês liderados por Mao Tze Tung. No pós-segunda guerra mundial, as ilhas ficam sobre administração do Estados Unidos, que a devolvem posteriormente à soberania ao Japão, sendo este fato contestado posteriormente pela China comunista, alegando ter direitos sobre a ilhas no pós-conflito pela conferência de Cairo de $1943^{5}$ e na Proclamação de Potsdam, de 19456, o Japão alega sobre a demanda chinesa, que a soberania das ilhas não está inclusa nos termos definitivos do Tratado de Paz de São Francisco, assinado posteriormente em 1951.

Além da pesca, a descoberta de óleo e gás natural em 1969 pela Comissão Econômica das Nações Unidas para a Ásia e o Extremo Oriente (ECAFE), relata a possibilidade da existência de depósitos de hidrocarbonetos nas profundezas próximas ao arquipélago Senkaku/Diaoyu, o que promovem o aumento das disputas (MINISTÉRIO DE NEGÓCIOS ESTRANGEIROS DO JAPÃO, 2012). Logo com as afirmações japonesas sobre a soberania nas ilhas, temos também em 1971, tanto da China comunista, como de Taiwan com seus refugiados nacionalistas,

\footnotetext{
5 Encontro entre Roosevelt (presidente dos EUA), Churchill (primeiro ministro-inglês) e Chiang Kai-Chek (presidente da China). O objetivo desse encontro era decidir o destino do império japonês, após a vitória da Ásia sobre o Japão. Ficou decidido que a China ficaria com todos os territórios tomados pelo Japão durante a guerra sino-japonesa. Os países tomados pelo Japão na Ásia reconquistaram a sua independência.

6 Declaração publicada em 26 de julho de 1945 por Harry S. Truman, Winston Churchill e Chiang Kai-shek, que traçaram os termos da rendição do Japão, conforme acordado na Conferência de Potsdam. A declaração estipulava que se o Japão não se rendesse, encararia "pronta e total destruição", determinava também severas imposições a soberania Japonesa na região e o desmantelamento de suas forças armadas.
} 
demandas internacionais sobre o direito a soberania das ilhas Senkaku/Diaoyu, criando-se um entrave diplomático de difícil resolução (MINISTÉRIO DE NEGÓCIOS ESTRANGEIROS DO JAPÃO, 2012).

Em 1978, as contestações foram atenuadas pelo Tratado Sino-japonês de Amizade e Paz, tratado este se fundamentava no aumento das relações bilaterais entre as partes na região em uma busca pela integração econômica e resoluções de conflitos. Acirraram-se os discursos junto a ONU com ações nacionalistas de ambas as partes, o Japão inicia uma campanha nacionalista em 2012 determinando a compra da ilha de seus proprietários particulares, transformando-as de bem privado oriundos de proprietários japoneses, em bens públicos administrados pelo Estado japonês. A China em represália intensifica sua patrulha naval sobre as ilhas e logo surgem movimentos de protestos contra empresas Japonesas com unidades residentes em solo Chinês (Honda e Panasonic).

A China protesta oficialmente em discurso junto a ONU em 28 de setembro de 2012, através de seu ministro de relações exteriores, declarando que o Japão estaria tentando subverter a lógica do Direito Internacional sobre as ilhas. Objetivando assim dificultar os trabalhos na busca por uma resolução, resolução está que sem dúvida determinara uma mudança significativa nas fronteiras marítimas e na zona de exclusão econômica (ZEE) para ambas as nações. A figura 2 abaixo demonstra as alterações nas fronteiras marítimas de ambos os países e as possíveis reservas de petróleo e gás descobertas: 


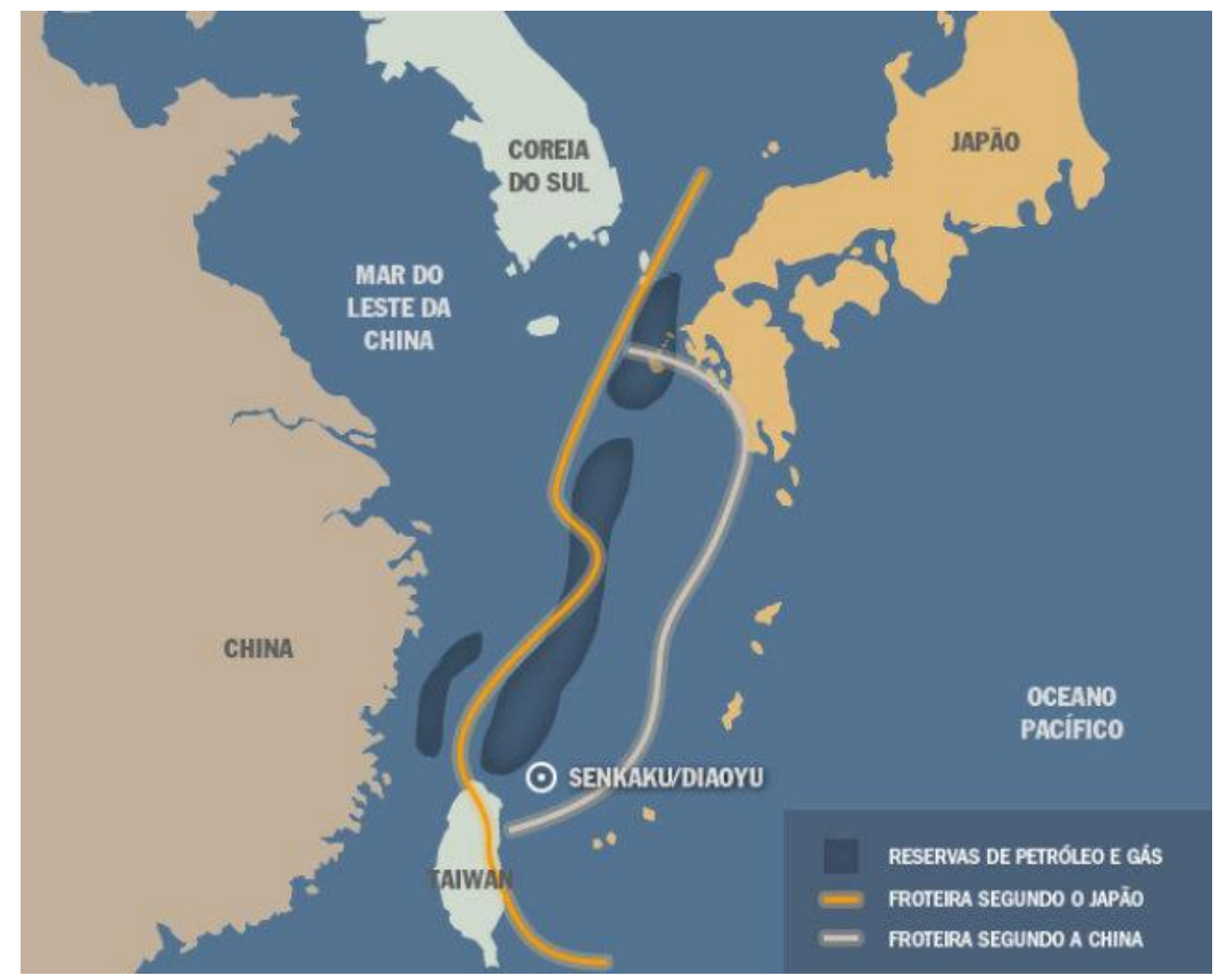

Figura 2. Fonte: Disponível em < http://veja.abril.com.br/noticia/mundo/por-que-oito-ilhotasopoem-china-e-japao >, acesso em 22 de abr. de 2015.

Os EUA tentam se colocar como mediador natural ao conflito, no entanto não recebe apoio por parte da China em seu intento, pois China o considera associado demais aos interesses japoneses, interesses estes ligados pelo compromisso de defesa firmado no "Pacto de Assistência e Segurança Mútua", ratificado em 1952 e como já demonstrado na ação Chinesa de projeção e fuga da contenção (Teoria das Fimbrias). A China preserva seu interesse em garantir sua relação com o Japão na forma bilateral e assim promove uma explicita diminuição da influência Norte Americana em sua área de atuação geopolítica.

\section{Considerações finais.}

A projeção Chinesa fundamentada na sua abertura de mercado e na projeção pacifica, garantiu que o sistema de contenção idealizados durante a guerra fria por Spykerman (1942), a OTASE, não se perpetuou como o ocorrido com a OTAN, a aproximação pragmática com os interesses dos EUA proporcionou a 
China uma das vias de sua ascensão. 0 Japão ao manter sua alta dependência em tratados internacionais de auxilio e cooperação militar com EUA, encara a necessidade de uma revisão constitucional sobre a projeção de suas forças armadas, revisão está que pode levar à diminuição do atual poder Norte Americano.

As reduções da influência da 7ํ frota do EUA sobre as regiões de interesse Chinês podem ir de encontro ao aumento da força naval Japonesa, desde que este aumento possa ser vinculado na garantia de área livre de armas nucleares, tal pretensão iriam assim de encontro aos acordos firmados pela China no tratado de Rarotonga de 1985. Em termos geopolíticos o aumento do poder geoestratégico (poder naval, poder terrestre e poder aéreo) por parte da China e Japão, podem propiciar um possível teatro de conflito armado na região, mas devido a capacidade de negociações bilaterais entre ambos e na necessidade mutua em assegurar os recursos naturais e energéticos, podemos ainda ter uma saída negociada para uma exploração pacifica e conjunta das áreas em disputa, saída esta também focada na convergência de uma maior integração econômica da região, consolidando os interesses da (Asean +3$)$.

\section{REFERÊNCIAS}

BONFIM, Uraci Castro, Curso de Política, Estratégia e Alta Administração do Exército: Geopolítica, Escola de Comando e Estado-Maior do Exército, 14 de jun., de 2005, disponível em: < http://www.ensino.eb.br/cpeceme/docs/03_INTRO_ GEOPOLITICA_2011.pdf >, acesso em 15 de nov. de 2014 .

Global Firepower Index, GFP, Word Military Powers, disponível em < http://www.globalfirepower.com/ > acesso em 01 de mar. de 2015.

MAHAN, AT, DCL, LL.D, A Influência do Poder do Mar pela sua História, BOSTON, editora Little, Brown and Company, 1890, disponível em: < http://www.gutenberg.org/files/13529/13529-h/13529-h.htm >, acesso em 19 de mar. de 2015.

MAKHINDER, H. John, The Geographical Pivot of History, the Geografic Journal, vol. 23, № 4, Apr. de 1904, 421-437, Disponível em < 
http://intersci.ss.uci.edu/wiki/eBooks/Articles/1904\%20HEARTLAND\%20THEO RY\%20HALFORD\%20MACKINDER.pdf >, acesso em 15 de mar. De 2015.

MEDEIROS, Roberto Carlos de, Reflexões sobre as ambições marítimas da China na atualidade, disponível em < http://www.sagres.org.br/artigos/ ambicoes_china_01.pdf > acesso em 12 de mar. de 2015 .

NOQUEIRA; Camila M. O. da Silva; A Atuação da China no Conselho de Segurança as Nações Unidas, 1971-2010; Universidade de São Paulo; Instituto de relações Internacionais, SP, 2012. Acesso em 22 mar. 2014. Disponível em www.teses.usp.br/teses/disponiveis/101/101131/tde-17072013-140331/.

PROCÓPIO, Agemiro, 0 capitalismo amarelo - relações internacionais da China, editora Juruá, 2012, DF - Brasília.

Ministério dos Negócios Estrangeiros do Japão, As Ilhas Senkaku: A Busca pela Paz Marítima baseada no Estado de Direito, não na força nem coerção, disponível em: http://www.br.embjapan.go.jp/territory/senkaku/pdfs/senkaku_pamphlet.pdf, acesso em 27 de abr. de 2015.

SPYKMAN, N. John, America's Strategy in World Politics: The United States and the Balance of Power, New York, Harcourt, Brace and Company (1942).

TOLOSSA, Natalia Valeria, A Política Europeia de Segurança e Defesa e a Formação da Identidade Coletiva: O CASO DO REINO UNIDO NO GOVERNO DE TONY BLAIR, PUC, RIO, 29 de set. de 2004, disponível em: http://www.maxwell.vrac.puc-rio.br/Busca_etds.php?strSecao=resultado\&nrSeq= 5513@1, acessoem 07 de abr.de 2015. 